\title{
Effect of La addition on thermal microstructural evolution of macroporous alumina monolith prepared from ionic precursors
}

\author{
Yasuaki TOKUDOME, Kazuki NAKANISHI ${ }^{\dagger}$ and Teiichi HANADA \\ Department of Chemistry, Graduate School of Science, Kyoto University, Kitashirakawa, Sakyo-ku, Kyoto $606-8502$
}

\begin{abstract}
Porous alumina monoliths with high thermal stability have been prepared using sol-gel processing from ionic precursors. Samples were synthesized from $\mathrm{AlCl}_{3} \cdot 6 \mathrm{H}_{2} \mathrm{O}$ and $\mathrm{LaCl}_{3} \cdot 7 \mathrm{H}_{2} \mathrm{O}$ dissolved in a $\mathrm{H}_{2} \mathrm{O}$ /etanol solution containing poly(ethylene oxide) (PEO) via propylene oxide (PO) involved sol-gel reaction accompanied by phase separation. The heat-treated gels consist of controllable size of macropores and La-doped alumina skeletons. Doped lanthanum ions are homogeneously embedded in the gel matrix, which retards the phase transition from $\gamma$-alumina to $\alpha$-alumina during the sintering. The 3 mol\% La-doped aluminate exhibits the BET surface area of $55.3 \mathrm{~m}^{2} / \mathrm{g}$, after the heat treatment at $1100^{\circ} \mathrm{C}$ for $24 \mathrm{~h}$. Drying condition are also related to the thermal stability of obtained gels. Aluminate aerogels show higher thermal stability than corresponding xerogels due to relatively large mesopore size and high porosity. As a result, the $3 \mathrm{~mol} \%$ lanthanum doped aluminate aerogel shows BET surface area as high as $82.5 \mathrm{~m}^{2} / \mathrm{g}$ even after heat treatment at $1100^{\circ} \mathrm{C}$ for $24 \mathrm{~h}$.
\end{abstract}

(C)2009 The Ceramic Society of Japan. All rights reserved.

Key-words : Porous alumina, Phase separation, Thermal stability, Propylene oxide, Lanthanum, Mesoporous

[Received December 1, 2008; Accepted January 15, 2009]

\section{Introduction}

Porous alumina having high surface area is valued for applications such as, catalytic reforming, hydroprocessing, and auto emission control, where durability at high-temperatures is required. ${ }^{1), 2)}$ One of the crucial problems, related to the use of porous alumina at high temperatures, is the reduction of surface area arising from phase transition and subsequent grain growth. Phase transition from metastable alumina phases into thermodynamically stable $\alpha$-alumina phase occurs above $1000^{\circ} \mathrm{C}$ to form sintered high density structure with the specific surface area $<10$ $\mathrm{m}^{2} / \mathrm{g}$. To overcome this difficulty, a doping of polyvalent cations has been attempted; cation additives with large ionic radius contribute to retard phase transition to the $\alpha$-phase. ${ }^{3), 4)}$ Among these additives, $\mathrm{La}^{3+}$ has been known to be particularly effective. ${ }^{5), 6)} \mathrm{A}$ widely accepted mechanism, which accounts for the stabilization of metastable phases by the $\mathrm{La}^{3+}$ addition, involves the formation of lanthanum aluminate phases. ${ }^{7), 8)}$ The phase transition from metastable phases into $\alpha$-phase is hindered by lanthanum aluminate layer formed onto alumina surface, thereby keeping BET surface area $>50 \mathrm{~m}^{2} / \mathrm{g}$ even after heating at $1100^{\circ} \mathrm{C}$. ${ }^{5}$

In most cases, stabilized aluminas are prepared in the shape of powder or membrane. $\mathrm{La}^{3+}$ is introduced by immersion of alumina particles to an aqueous lanthanum nitrate solution. Subsequent drying and heat treatment processes produce stabilized alumina powder. ${ }^{5), 9)}$ For stabilized alumina membrane, dip coating with a mixture of aluminate sol and lanthanum nitrate is utilized. ${ }^{10)}$ However, there has been hardly any report on the lanthanum-modified porous alumina in a monolithic form. Monolithic macroporous material has significant advantage in the application to catalytic reaction due to its low resistance to

Corresponding author: K. Nakanishi; E-mail: kazuki@kuchem. kyoto-u.ac.jp liquid or gas flow and high mechanical strength which are required for severe conditions. ${ }^{11)}$

In the present study, we focus on the fabrication of La-doped porous alumina monolith and its phase transition behavior on heating. La-incorporated porous aluminate gel, which was converted into porous alumina after calcinations, was synthesized from ionic precursors via one-pot sol-gel route. ${ }^{12), 13)}$ Starting from $\mathrm{AlCl}_{3} \cdot 6 \mathrm{H}_{2} \mathrm{O}$ and $\mathrm{LaCl}_{3} \cdot 7 \mathrm{H}_{2} \mathrm{O}$ dissolved in a mixed ethanol/ water solvent, monolithic gels were prepared by the addition of propylene oxide. ${ }^{14)}$ Macroporous structure was formed as a result of phase separation induced by an incorporation of poly(ethylene oxide). ${ }^{15)}$ Homogeneous dispersion of doped ions in a gel matrix was confirmed. Also facile sol-gel synthesis route enabled to design the mesoporous structures with resistance to extensive sintering. In this paper, we examined the effect of lanthanum ion additive and mesoporous morphology on the phase transition behavior and surface area.

\section{Experimental procedure}

\subsection{Materials}

Aluminum chloride hexahydrate $\left(\mathrm{AlCl}_{3} \cdot 6 \mathrm{H}_{2} \mathrm{O}\right.$ : Aldrich, 99\%) was used as an aluminum source, and a mixture of distilled $\mathrm{H}_{2} \mathrm{O}$ and ethanol (EtOH: Kishida Chemical Co., Ltd., 99.5\%) as a solvent. Lanthanum chloride heptahydrate $\left(\mathrm{LaCl}_{3} \cdot 7 \mathrm{H}_{2} \mathrm{O}\right.$ : Kishida Chemical Co., Ltd., 97\%) was used as a rare earth metal chloride additive. Propylene oxide (PO: Aldrich, $\geq 99 \%$ ) was added to initiate condensation reaction, ${ }^{14)}$ and poly(ethylene oxide) (PEO: Aldrich) having viscosity-averaged molecular weight $\left(M_{\mathrm{v}}\right)$ of 1 $\times 10^{6}$ was used as a phase separation inducer. ${ }^{15)}$ All reagents were used as received.

\subsection{Synthesis}

All the samples were synthesized setting the total amount of $\mathrm{AlCl}_{3} \cdot 6 \mathrm{H}_{2} \mathrm{O}$ and $\mathrm{LaCl}_{3} \cdot 7 \mathrm{H}_{2} \mathrm{O}$ at $17.89 \mathrm{mmol}$. Aluminate gels 
doped with $0,1,3,5,7$, and $10 \mathrm{~mol} \%$ of $\mathrm{LaCl}_{3} \cdot 7 \mathrm{H}_{2} \mathrm{O}$ were synthesized. Samples were prepared by slightly modifying our previously reported procedure for the macroporous alumina monoliths. ${ }^{12)}$ The molar composition of a starting solution was $\left(\mathrm{AlCl}_{3} \cdot 6 \mathrm{H}_{2} \mathrm{O}+\mathrm{LaCl}_{3} \cdot 7 \mathrm{H}_{2} \mathrm{O}\right): \mathrm{PEO}: \mathrm{H}_{2} \mathrm{O}: \mathrm{EtOH}: \mathrm{PO}=1.0: 4.47 \times$ $10^{-6}: 12.4: 5.27: 3.00 . \mathrm{AlCl}_{3} \cdot 6 \mathrm{H}_{2} \mathrm{O}, \mathrm{LaCl}_{3} \cdot 7 \mathrm{H}_{2} \mathrm{O}$, and PEO were dissolved in a mixture of distilled $\mathrm{H}_{2} \mathrm{O}$ and EtOH. Then, under ambient condition $\left(25^{\circ} \mathrm{C}\right)$, PO was added. After stirring for $1 \mathrm{~min}$, the reaction solution thus prepared was transferred to a closed vessel and kept at $40^{\circ} \mathrm{C}$. After gelation, the wet gel was aged for $24 \mathrm{~h}$ at $40^{\circ} \mathrm{C}$. Some of the wet gels were evaporatively dried at $40^{\circ} \mathrm{C}$. The other wet gels were subjected to the 5 -fold solvent exchange with 2-propanol and dried with supercritical $\mathrm{CO}_{2}$ drying system (Mitsubishi Material Techno Corp.). Both evaporatively dried and supercritically dried gels were heat-treated in air at $1100^{\circ} \mathrm{C}$ for various time periods.

\subsection{Characterization}

A scanning electron microscope equipped with the energydispersive X-ray analyzer (SEM-EDX: JSM-6060 + JED-2300, JEOL Ltd.) was employed to observe morphology of samples with Pt-Pd coating. A field emission scanning electron microscope (FE-SEM: JSM-6700F, JEOL Ltd.) was used to examine fine structure of heat-treated gels. Micro-mesoporous structure was characterized by a $\mathrm{N}_{2}$ adsorption-desorption isotherm (BELSORP-mini, Bel Japan Inc., Japan). The pore size distribution was calculated from the adsorption branch of the isotherm by the Barrett-Joyner-Halenda (BJH) method and the surface area was obtained by the Brunauer-Emmett-Teller (BET) method. Before measurement, the sample was outgassed under vacuum at $200^{\circ} \mathrm{C}$. The $\mathrm{La} /(\mathrm{La}+\mathrm{Al})$ atomic ratios in dried gels were measured by inductively coupled plasma optical emission spectrometer (ICP-OES: SPS 6100, SII Nano Technology Inc., Japan). The X-ray diffraction (XRD) analysis was carried out to identify the crystalline phases with RINT system $(2 \mathrm{~kW}, \mathrm{Cu} \mathrm{K} \alpha$ : $\lambda=0.154 \mathrm{~nm}$, RINT-Ultima III, Rigaku Corp.).

\section{Results and discussion}

Ionic precursors, such as $\mathrm{AlCl}_{3} \cdot 6 \mathrm{H}_{2} \mathrm{O}$ and $\mathrm{LaCl}_{3} \cdot 7 \mathrm{H}_{2} \mathrm{O}$, were stable in a solvent containing PEO, and a homogeneous mixing of starting components was readily achieved. The starting solutions were initially homogeneous and transparent. As time elapses, the phase separation and the gelation proceeded spontaneously in a closed and static condition. The white opaque gels were obtained with the gelation time of ca. $10 \mathrm{~min}$ in a monolithic form. When the PO is added to the reaction solution, PO acts as proton scavenger to give rise to homogeneous increase in $\mathrm{pH}$ of the solution. ${ }^{14)}$ Slow and homogeneous increase in $\mathrm{pH}$ allows homogeneous condensation of metal hydroxide species, which results in monolithic hydroxide gels. Starting from highly acidic solution, $\mathrm{pH}$ of the solution elevates gradually, and aluminum hydroxide precipitates are first formed. This is because the aluminum hydroxide is less soluble than lanthanum hydroxide. Then, lanthanum hydroxide species precipitate onto the interface of aluminum hydroxide embryos and the surrounding solution, because of local proton deficiency as reported in the case of coprecipitation. ${ }^{16)}$ As the reaction proceeds, the lanthanum ion incorporated aluminum hydroxide species are phase-separated from a reaction solution via spinodal decomposition, and consequently form interconnected two phases, i.e. gel phase and fluid phase. Subsequent solidification of the gel phase results in a two-phase wet gel having micrometer range heterogeneity. Macroporous structure can be obtained after removal of the fluid phase by drying.

Scanning electron microscope (SEM) images of evaporatively dried aluminate gels containing lanthanum at various concentrations are shown in Fig. 1. Interconnected macropores and gel skeletons are observed in all the samples. In addition, small particles attached on the gel skeletons are recognized in the Figs. 1(b)-(f). This kind of morphology is observed as a result of secondary phase separation ${ }^{15)}$ and not as a result of segregation of lanthanum hydroxide species, which is confirmed by SEM-EDX observation (not shown). The concentrations of lanthanum in dried gels measured by ICP-OES, compared with the respective nominal concentrations in the parentheses, were 1.00 (1.00), 3.11 (3.00), 4.79 (5.00), 6.49 (7.00), and 9.23 (10.0) mol\%. These measured values indicate that less than $10 \%$ of initially doped lanthanum was lost during drying of the gel specimens. In spite of the shrinkage during the heating process, macroporous morphology is maintained even after heat treatment at $1100^{\circ} \mathrm{C}$, as shown in Fig. 2. Heat-treated gels are obtained in a monolithic form with the dimensions of $5 \times 5 \times 5 \mathrm{~mm}^{3}$.

Figure 3 shows XRD patterns of heat-treated aluminate gels containing lanthanum at various concentrations. Additive-free sample shows sharp diffraction lines ascribed to $\alpha$-alumina phase (Fig. 3(a)). By contrast, phase transition from $\gamma$-alumina to $\alpha$-alumina is retarded by only $1 \mathrm{~mol} \% \mathrm{La}$ addition (Fig. 3(b)). Up to $3 \mathrm{~mol} \%$ addition of lanthanum, observable phase is only $\gamma$-alumina (Fig. 3(c)). Further addition of La produces lanthanum- $\beta$-alumina phase $\left(\mathrm{La}_{2} \mathrm{O}_{3} \cdot 11 \mathrm{Al}_{2} \mathrm{O}_{3}\right)$ (Fig. $3(\mathrm{~d})$, (e)). It has been pointed out that lanthanum- $\beta$-alumina phase is formed with relatively low surface lanthanum concentration ${ }^{8}{ }^{8}$ suggesting that doped lanthanum ions are homogeneously dispersed in a gel matrix without segregation. As doped $\mathrm{La}$ is increased to 10 mol\%, non-negligible concentration of La results in the forma-

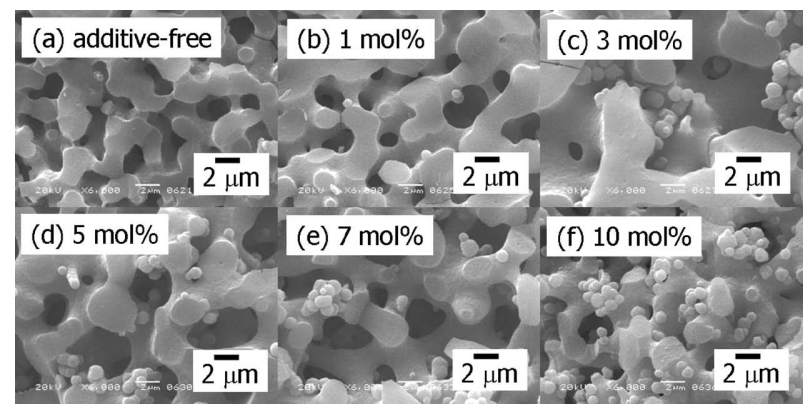

Fig. 1. SEM images of evaporatively dried aluminate gels containing lanthanum at various concentrations.

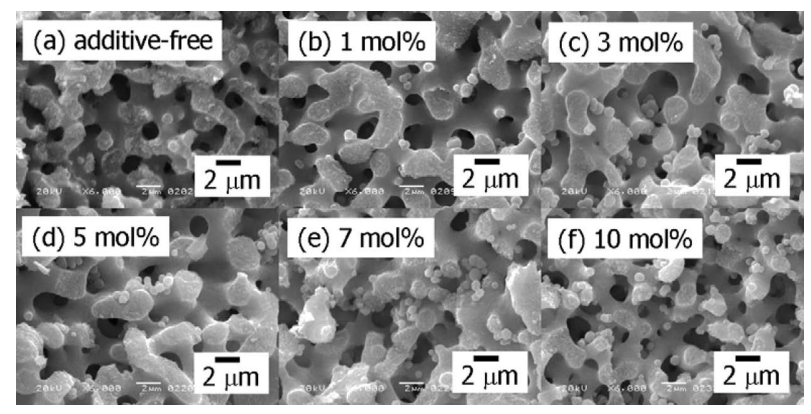

Fig. 2. SEM photographs of heat-treated aluminte gels containing lanthanum at various concentrations. Heat treatment was carried out at $1100^{\circ} \mathrm{C}$ for $24 \mathrm{~h}$ 
tion of $\mathrm{LaAlO}_{3}$ (Fig. 3(f)). Lanthanum aluminate phase is known to be formed as a result of high concentrated $\mathrm{La}$ on the alumina surface. When the La-doped alumina is synthesized via coprecipitation method, ${ }^{17)} \mathrm{LaAlO}_{3}$ phase is observed with high content of $\mathrm{La}^{3+}$ addition. A homogeneous dispersion of doped ion in alumina surface requires high concentration of additives to form $\mathrm{LaAlO}_{3} ; 10 \mathrm{~mol} \%$ La-doped alumina shows $\mathrm{LaAlO}_{3}$ phase after calcinations at $1200^{\circ} \mathrm{C} .{ }^{18)}$ Thus, the emergence of $\mathrm{LaAlO}_{3}$ in this study is also considered to be the evidence of the homogeneous dispersion of doped ions.

Dependence of BET surface area of aluminate gels on sintering time is depicted in Fig. 4. The additive-free aluminate gel shows steep decrease of BET surface area with sintering time, and eventually $6.6 \mathrm{~m}^{2} / \mathrm{g}$ after heat-treated at $1100^{\circ} \mathrm{C}$ for $24 \mathrm{~h}$. On the other hand, La-doped samples show relatively high thermal stability. Surface area increases with concentration of additives

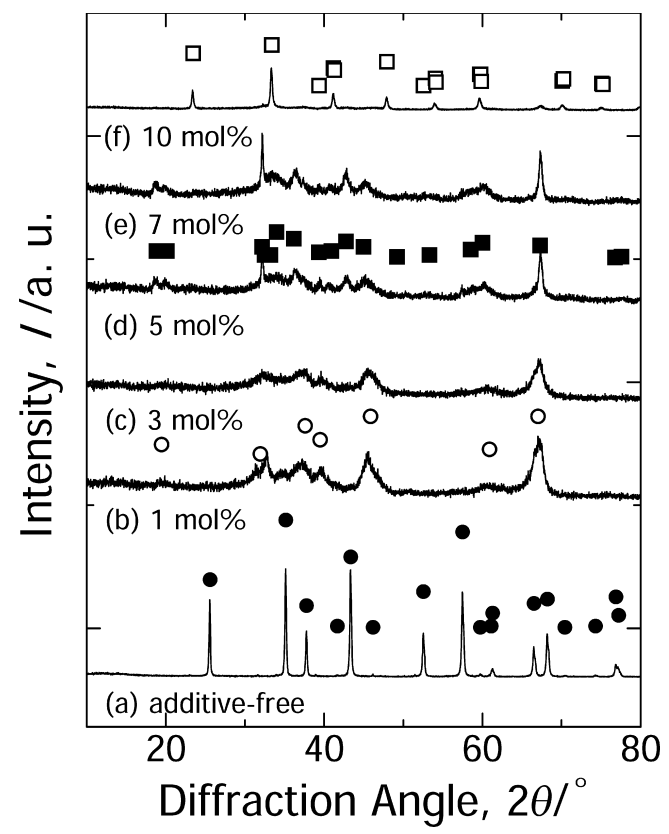

Fig. 3. XRD patterns of heat-treated aluminate gels containing lanthanum at various concentrations. Heat treatment was carried out at $1100^{\circ} \mathrm{C}$ for $24 \mathrm{~h}$. Symbols represent following phases; closed circle: $\alpha-\mathrm{Al}_{2} \mathrm{O}_{3}$, open circle: $\gamma-\mathrm{Al}_{2} \mathrm{O}_{3}$, closed square: lanthanum- $\beta$-alumina, open square: $\mathrm{LaAlO}_{3}$.

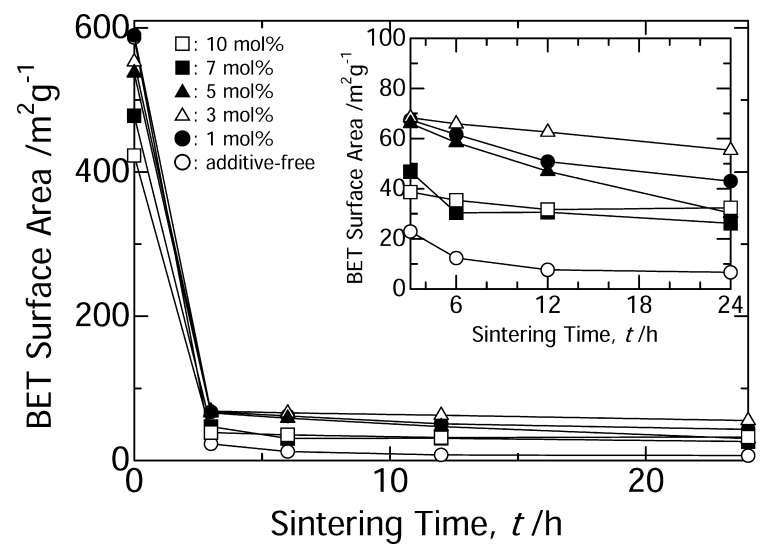

Fig. 4. Dependence of BET surface area of aluminate gels on sintering time. up to $3 \mathrm{~mol} \%$. The $3 \mathrm{~mol} \%$ La-doped aluminate exhibits the BET surface area as high as $55.3 \mathrm{~m}^{2} / \mathrm{g}$, even after the heat treatment at $1100^{\circ} \mathrm{C}$ for $24 \mathrm{~h}$. Effective suppression of sintering for $3 \mathrm{~mol} \%$ La-doped aluminate can be related to the formation of lanthanum- $\beta$-alumina phase detected by XRD analysis. Stabilizing effect reaches a maximum at $3 \mathrm{~mol} \%$ doping, and further addition of lanthanum reduces the surface area. This behavior can be interpreted by the loss of surface area due to the grain growth of lanthanum aluminate phases.

Figure 5 shows FE-SEM images of fractured surface of the gel skeleton after heat treatment at $1100^{\circ} \mathrm{C}$ for $24 \mathrm{~h}$. The additive-free aluminate gives significantly sintered structure with low surface area (Fig. 5(a)). By contrast, sintering of $3 \mathrm{~mol} \%$ doped sample, which exhibits the highest surface area, is suppressed considerably (Fig. 5(b)). Further addition of lanthanum results in the growth of primary particles (Figs. 5(c), (d)), which is consistent with the results from XRD analysis and $\mathrm{N}_{2}$-adsorption measurement. Needle-like morphology in Fig. 5(c) is derived from anisotropic lanthanum- $\beta$-alumina crystals, based on the result of XRD analysis in Fig. 3(e). A sharp peak with abnormally high intensity of (110) diffraction line at $32.16^{\circ}$ indicates the anisotropic growth of lanthanum- $\beta$-alumina crystals dispersed in the gel skeletons. In a similar fashion, the growth of primary particles in the $10 \mathrm{~mol} \%$ La doped aluminate can be attributed to the crystal

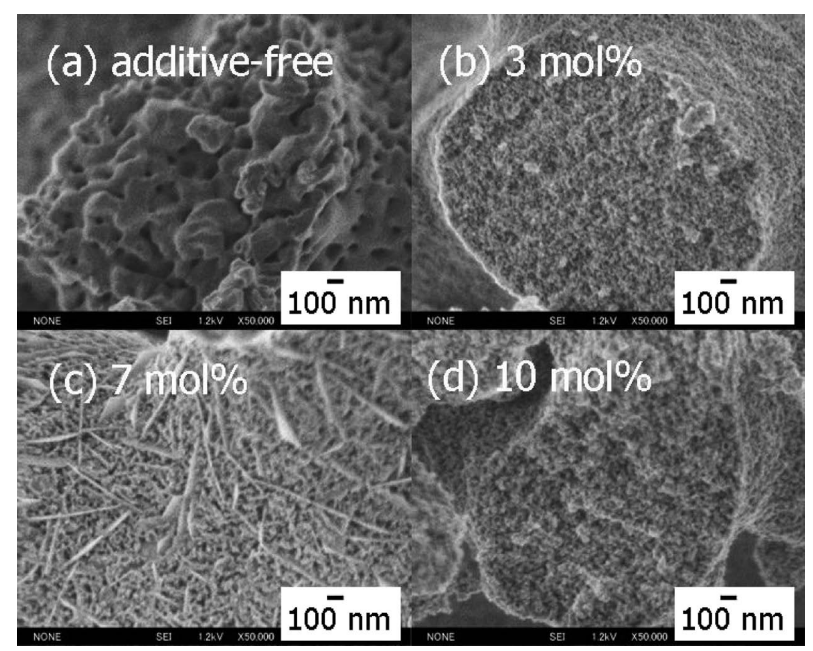

Fig. 5. Fine structures of La-doped aluminate gels after heat-treated at $1100^{\circ} \mathrm{C}$ for $24 \mathrm{~h}$. (a) Dried gels

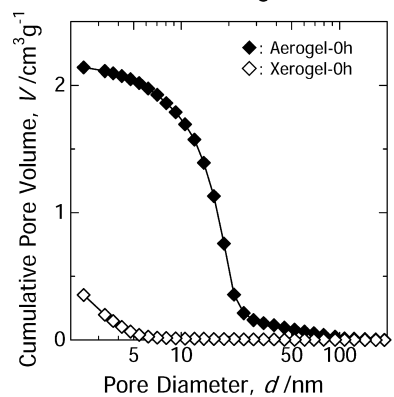

(b) Heat-treated gels

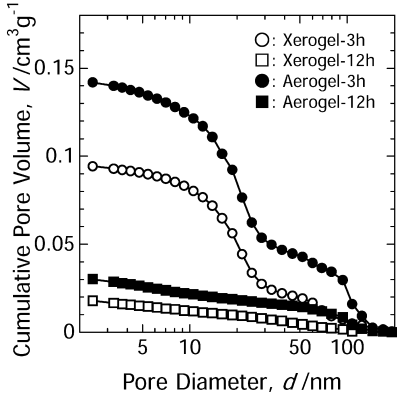

Fig. 6. Relation between the pore diameter and the cumulative pore volume of additive-free (a) dried gels and (b) heat-treated gels. Samples were heat-treated at $1100^{\circ} \mathrm{C}$ in air for various time periods. 
Table 1. Relationship Between Pore Properties of Dried Gels and BET Surface Area of Heat-treated Gels

\begin{tabular}{cccccr}
\hline $\begin{array}{c}\mathrm{La} /(\mathrm{La}+\mathrm{Al}) \\
(\mathrm{mol} \%)\end{array}$ & & $\begin{array}{c}\text { Median pore size } \\
(\mathrm{nm})\end{array}$ & $\begin{array}{c}\text { Mesopore volume\# } \\
(\mathrm{cc} / \mathrm{g})\end{array}$ & \multicolumn{2}{c}{$\begin{array}{c}\text { BET surface } \operatorname{area~}\left(\mathrm{m}^{2} / \mathrm{g}\right)^{*} \\
24\end{array}$} \\
\hline 0 & Xerogel & 3.17 & 0.35 & 7.6 & 6.6 \\
1 & Xerogel & 3.39 & 0.41 & 50.8 & 43.0 \\
3 & Xerogel & 3.70 & 0.42 & 62.6 & 55.3 \\
0 & Aerogel & 17.61 & 2.13 & 9.3 & 8.6 \\
1 & Aerogel & 16.47 & 1.86 & 76.8 & 67.1 \\
3 & Aerogel & 17.42 & 1.81 & 91.0 & 82.5 \\
\hline
\end{tabular}

\# Pore volume up to $100 \mathrm{~nm}$ calculated from BJH method.

* BET surface areas after heat-treated at $1100^{\circ} \mathrm{C}$ for $12 \mathrm{~h}$ and $24 \mathrm{~h}$.

growth of $\mathrm{LaAlO}_{3}$.

Aluminate gels prepared in this study shrink significantly in the course of evaporative drying because of capillary force. Sintering is related to the densification of gel network, and hence thermal behavior depends on the porosity and the structure in the nanometer scale. ${ }^{19), 20)}$ Thus, the modification of network structure is another approach to obtain porous alumina with high thermal stability. In order to obtain shrinkage-free and highly porous alumina, supercritical drying was employed in this study. Supercritical drying is one of the promising routes to suppress the deformation of fragile porous materials by capillary force during the evaporative drying. Thermal stabilities of supercritically dried gels were compared with those of evaporatively dried gels. Figure 6 shows the relation between the pore diameter and the cumulative pore volume of additive-free (a) dried gels and (b) heat-treated gels. A shrinkage-free aerogel possesses larger median mesopore size and mesopore volume than the corresponding xerogel, as depicted in Fig. 6(a). Both aerogel and xerogel exhibit a decrease of the pore volume and an increase of the pore diameter with prolonged heating time at $1100^{\circ} \mathrm{C}$. However, aerogel possesses relatively higher pore volume, i.e. higher thermal stability, than xerogel, as indicated by the result in Fig. 6(b). In alkoxy-derived alumina sol-gel system, alumina gels dried using supercritical $\mathrm{CO}_{2}$ exhibit a pentahedrally coordinated Al structure, which hinders the formation of $\theta$-alumina from the $\gamma$-phase. ${ }^{21)}$ Also, in this study, the coordination environment of $\mathrm{Al}$ atom in aerogel is possibly different from that in xerogel. Thus, further experiments are required to reveal the factors which influence on the thermal stability between aerogels and xerogels.

Finally, in order to obtain alumina with high surface area, Ladoped aluminate aerogels were also synthesized. Pore properties of La-doped aluminate aerogels and La-doped aluminate xerogels are listed in Table 1. The concentrations of lanthanum in supercritically dried gels measured by ICP-OES were 0.93 and $2.83 \mathrm{~mol} \%$ for 1.00 and $3.00 \mathrm{~mol} \%$ doped samples, respectively, indicating most of the doped lanthanum remain in gel matrix even after the 5-fold solvent exchange with 2-propanol and subsequent $\mathrm{CO}_{2}$ supercritical drying process. Sintering of aerogel is suppressed by lanthanum doping, as in the case of xerogel, and BET surface area of aerogel increases with the concentration of lanthanum ion. With an identical concentration of lanthanum, aerogel exhibits higher thermal stability than xerogel due to their higher porosity and larger mesopore size. The highly porous structure and the lanthanum doping contribute to the high thermal stability, and as a result, $3 \mathrm{~mol} \%$ lanthanum doped aluminate aerogel shows BET surface area as high as $82.5 \mathrm{~m}^{2} / \mathrm{g}$ even after heat treatment at $1100^{\circ} \mathrm{C}$ for $24 \mathrm{~h}$

Further improvement of thermal stability requires precise control of structural factors, such as porosity, pore size, and crystallinity of starting materials. ${ }^{22)}$ The use of surfactants and drying control chemical additives (DCCA) is another potential approach to suppress the shrinkage during drying process. Also, reinforcement of gel network using polymers and metal alkoxides contributes to produce low shrinkage aluminate gels. We continue focusing on the precise control of pore properties in nanometer scale for alumina with improved thermal stability, of which details will be reported elsewhere.

\section{Conclusions}

Lanthanum-modified porous aluminas have been prepared in a monolithic form. Lanthanum ions dissolved in a starting solution are incorporated into aluminate gel matrix during the solgel transition. The heat-treated gels show macropores and lanthanum doped alumina skeletons. The results of FE-SEM observation and XRD measurement indicate that doped lanthanum ions are homogeneously dispersed in the gel matrix without segregation, which retards the phase transition from $\gamma$-alumina to $\alpha$-alumina during the sintering. The $3 \mathrm{~mol} \% \mathrm{La}$-doped aluminate exhibits the BET surface area of $55.3 \mathrm{~m}^{2} / \mathrm{g}$, after the heat treatment at $1100^{\circ} \mathrm{C}$ for $24 \mathrm{~h}$. Also, suppression of shrinkage during drying process influences on thermal stability of aluminates. Aluminate aerogels having large mesopore and high porosity show higher thermal stability than corresponding xerogels. The $3 \mathrm{~mol} \%$ lanthanum doped aluminate aerogel shows BET surface area as high as $82.5 \mathrm{~m}^{2} / \mathrm{g}$ even after heat treatment at $1100^{\circ} \mathrm{C}$ for $24 \mathrm{~h}$.

Acknowledgement This work was partly supported by the Grant-in-Aid for Scientific Research (No. 20350094) from MEXT, Japan and the Grant for Practical Application of the University R\&D Results under the Matching Fund Method from NEDO, Japan. Y. T. was supported by the research fellowship of global COE program (\#B-024), International Center for Integrated Research and Advanced Education in Material Science, Kyoto University, Japan. The authors thank Prof. Hiroyuki Nakagawa and Mr. Yoshiji Honda, Environmental Preservation Center, Kyoto University for ICP-OES analysis.

\section{References}

1) J. C. Downing and K. P. Goodboy, "Claus Catalysis and Alumina Catalyst Materials and Their Application," Am. Chem. Soc., Washington, DC. (1990).

2) F. Schüth, K. S. W. Sing and J. Weitkamp, "Handbook of 
Porous Solids," Wiley, New York (2002).

3) P. Burtin, J. P. Brunelle, M. Pijolat and M. Soustelle, Appl. Catal., 34, 225-238 (1987).

4) K. Okada, A. Hattori, T. Taniguchi, A. Nukui and R. N. Das, J. Am. Ceram. Soc., 83[4], 928-932 (2000).

5) H. Schaper, E. B. M. Doesburg and L. L. Van Reijen, Appl. Catal., 7, 211-220 (1983).

6) J. S. Church, N. W. Cant and D. L. Trimm, Appl. Catal. A, 101, 105-116 (1993).

7) M. Bettman, R. E. Chase, K. Otto and W. H. Weber, J. Catal., 117, 447-454 (1989).

8) L. P. Haack, C. R. Peters, J. E. de Vries and K. Otto, Appl. Catal. A, 87, 103-114 (1992).

9) M. Ozawa and M. Kimura, A. Isogai, J. Less-Common Met., 162, 297-308 (1990).

10) Y. S. Lin and A. J. Burggraaf, J. Am. Ceram. Soc., 74, 219224 (1991).

11) R. M. Heck, S. Gulati and R. J. Farrauto, Chem. Eng. J., 82, 149-156 (2001).

12) Y. Tokudome, K. Fujita, K. Nakanishi, K. Miura and K. Hirao, Chem. Mater., 19, 3393-3398 (2007).
13) Y. Tokudome, K. Fujita, K. Nakanishi, K. Kanamori, K. Miura, K. Hirao and T. Hanada, J. Ceram. Soc. Japan, 115[12], 925-928 (2007).

14) A. E. Gash, T. M. Tillotson, J. H. Satcher Jr., J. F. Poco, L. W. Hrubesh and R. L. Simpson, Chem. Mater., 13, 999-1007 (2001).

15) K. Nakanishi, J. Porous Mater., 4, 67-112 (1997).

16) Q. Chen, A. J. Rondinone, B. C. Chakoumakos and Z. J. Zhang, J. Magn. Magn. Mater., 194, 1-7 (1999).

17) C. K. Narula, J. E. Allison, D. R. Bauer and H. S. Gandhi, Chem. Mater., 8, 984-1003 (1996).

18) A. Kato, H. Yamashita, H. Kawagoshi and S. Matsuda, J. Am. Chem. Soc., 70[7], C-157-C-159 (1987).

19) B. E. Yoldas, J. Mater. Sci., 10, 1856-1860 (1975).

20) S. Keysar, G. E. Shter, Y. de Hazan, Y. Cohen and G. S. Grader, Chem. Mater., 9, 2464-2467 (1997).

21) Y. Mizushima, M. Hori and M. Sasaki, J. Mater. Res., 8, 2109-2111 (1993).

22) A. C. Pierre, E. Elaloui and G. M. Pajonk, Langmuir, 14, 6673 (1998). 